The ASMBS Textbook of Bariatric Surgery 

Christopher Still - David B. Sarwer Jeanne Blankenship

Editors

\section{The ASMBS Textbook of Bariatric Surgery}

Volume 2: Integrated Health

说 Springer 


\section{Editors}

Christopher Still

Department of GI and Nutrition

Geisinger Obesity Institute

Geisinger Medical Center

Danville, PA, USA

Jeanne Blankenship

Policy Initiatives and Advocacy

American Dietetic Association

Falls Church, VA, USA
David B. Sarwer

Professor of Psychology

Departments of Psychiatry

Director of Clinical Services

Center for Weight and Eating Disorders

Perelman School of Medicine

at the University of Pennsylvania

Philadelphia, PA, USA

ISBN 978-1-4939-1196-7

ISBN 978-1-4939-1197-4 (eBook)

DOI 10.1007/978-1-4939-1197-4

Springer New York Heidelberg Dordrecht London

Library of Congress Control Number: 2014945755

(C) Springer Science+Business Media New York 2014

This work is subject to copyright. All rights are reserved by the Publisher, whether the whole or part of the material is concerned, specifically the rights of translation, reprinting, reuse of illustrations, recitation, broadcasting, reproduction on microfilms or in any other physical way, and transmission or information storage and retrieval, electronic adaptation, computer software, or by similar or dissimilar methodology now known or hereafter developed. Exempted from this legal reservation are brief excerpts in connection with reviews or scholarly analysis or material supplied specifically for the purpose of being entered and executed on a computer system, for exclusive use by the purchaser of the work. Duplication of this publication or parts thereof is permitted only under the provisions of the Copyright Law of the Publisher's location, in its current version, and permission for use must always be obtained from Springer. Permissions for use may be obtained through RightsLink at the Copyright Clearance Center. Violations are liable to prosecution under the respective Copyright Law.

The use of general descriptive names, registered names, trademarks, service marks, etc. in this publication does not imply, even in the absence of a specific statement, that such names are exempt from the relevant protective laws and regulations and therefore free for general use.

While the advice and information in this book are believed to be true and accurate at the date of publication, neither the authors nor the editors nor the publisher can accept any legal responsibility for any errors or omissions that may be made. The publisher makes no warranty, express or implied, with respect to the material contained herein.

Printed on acid-free paper

Springer is part of Springer Science+Business Media (www.springer.com) 


\section{Preface}

The American Society for Metabolic and Bariatric Surgery (ASMBS) is comprised of a dynamic group of surgeons, physicians, and integrated health members, all of whom are constantly challenged to improve the care of obese patients. As acknowledged in a landmark 2013 decision by the American Medical Association, clinically severe obesity is a disease process that is associated with multiple life-threatening conditions that may lead to premature death. As repeatedly and consistently demonstrated by literature evidence, bariatric surgery has shown to be the only long-lasting effective treatment for obesity and its related comorbidities.

Due to the development of videoscopic instrumentation, critical care, modern stapling devices, and laparoscopy, the field of bariatric surgery has changed tremendously over that past three decades since ASMBS's founding in 1983. Until 1998, only 10,000-12,000 bariatric operations were being performed yearly in the United States, with high rates of morbidity and mortality. This number of operations has increased exponentially over the subsequent years and eventually peaked at more than 140,000 operations in 2004. This growth directly correlates with the development and transition from open to laparoscopic Roux-en-Y gastric bypass. Additionally in 2001, following the US Food and Drug Administration's approval of the laparoscopic adjustable gastric band, the number of bariatric procedures experienced a significant increase. By 2005, the number of laparoscopic Roux-en-Y gastric bypass cases being performed in the United States surpassed the number of open Roux-en-Y gastric bypass cases. Most recently, the laparoscopic sleeve gastrectomy has proven to be an additional effective bariatric surgical option, with a risk and benefit profile between that of laparoscopic gastric bypass and laparoscopic adjustable gastric banding.

Along with those utilization changes, technological advancement, surgical technique, and quality improvement all required our society to respond to and accommodate the educational needs of our members. This dynamic field of surgery will continue to grow with enhanced understanding of the mechanisms of action of the procedures we can offer and the development of innovative and complementary treatment of obesity. As the needs of the society and its members evolve, the ASMBS is committed to continuing to serve the educational needs of our members and expanding public education. Our annual meeting is the primary venue to disseminate new information and educational materials to clinical professionals. To enhance and augment these educational offerings, we are excited to present this comprehensive ASMBS textbook of bariatric surgery. The development of this book reflects the commitment of the ASMBS leadership's goal of providing the most up-to-date education for our members.

Designed to be the most inclusive textbook on the topic of bariatric surgery and integrated health services to date, this textbook comprises two volumes. The first volume is devoted to the science and practices of bariatric surgery and is divided into five sections detailing basic considerations, including bariatric surgery's history and evolution, the pathophysiology of obesity, mechanisms of action, primary operations and management of complications, revision of primary bariatric surgery for failure of weight loss, the role of metabolic surgery, and specific considerations such as the role of endoscopy in bariatric surgery and coding and reimbursement. The second volume focuses on the medical, psychological, and nutritional management of the bariatric patients. 
Each chapter in this book was written by a world-renowned expert in their field. A comprehensive text that adheres to the highest standards is a major undertaking, and we, the editors, are grateful and indebted to every author who has devoted time and effort to research the most important evidence-based information and report it in a concise and easy-to-read chapter. We believe that this ASMBS Textbook of Bariatric Surgery is the leading source of scientific information for surgeons, physicians, residents, students, and integrated health members today and for years to come.

Orange, CA, USA

Scottsdale, AZ, USA

Standford, CA, USA

Dalton, GA, USA

University Park, FL, USA

Falls Church, VA, USA

Philadelphia, PA, USA

Danville, PA, USA
Ninh T. Nguyen, MD

Robin Blackstone, MD

John Morton, MD

Jaime Ponce, MD

Raul Rosenthal, MD

Jeanne Blankenship, RD

David B. Sarwer, PhD

Christopher Still, DO 


\section{Contents}

Part I Psychosocial

1 Psychosocial Characteristics of Bariatric Surgery Candidates.

David B. Sarwer, Kelly C. Allison, Brooke A. Bailer, and Lucy F. Faulconbridge

2 Psychopathology and Bariatric Surgery

James E. Mitchell and Martina de Zwaan

3 Quality of Life

David B. Sarwer, Chanelle T. Bishop-Gilyard, and Ray Carvajal

4 Eating Disorders and Eating Behavior Pre- and Post-bariatric Surgery Martina de Zwaan and James E. Mitchell

5 Introduction to Psychological Consultations for Bariatric Surgery Patients.

Katherine L. Applegate and Kelli E. Friedman

6 Psychosocial Issues After Bariatric Surgery

Leslie J. Heinberg and Megan E. Lavery

7 Technology to Assess and Intervene on Weight-Related Behaviors with Bariatric Surgery Patients.

J. Graham Thomas and Dale S. Bond

8 Psychosocial Issues in Adolescent Bariatric Surgery

Meg H. Zeller and Jennifer Reiter-Purtill

\section{Part II Nutrition}

9 Perioperative Nutrition Assessment of the Bariatric Surgery Patient Laura Lewis Frank

10 Nutrition Education and Counseling of the Bariatric Surgery Patient Toni Piechota

11 Macronutrient Recommendations: Protein, Carbohydrate, and Fat. Mary Demarest Litchford

12 Identification, Assessment, and Treatment of Vitamin and Mineral Deficiencies After Bariatric Surgery Margaret M. Furtado

13 Managing Common Nutrition Problems After Bariatric Surgery Claire M. LeBrun 
14 Nutrition Care Across the Weight Loss Surgery Process

Julie M. Parrott and J. Scott Parrott

\section{Part III Obesity Medicine}

15 Lifestyle Modification for the Treatment of Obesity

David B. Sarwer, Meghan L. Butryn, Evan Forman, and Lauren E. Bradley

16 Pharmacotherapy Management of Obesity

Amanda G. Powell and Caroline Apovian

17 Medical Preparation for Bariatric Surgery

Peter N. Benotti and Gregory Dalencourt

18 The Perioperative and Postoperative Medical Management of the Bariatric Surgery Patient

Christopher Still, Nadia Boulghassoul-Pietrzykowska, and Jennifer Franceschelli

19 The Importance of a Multidisciplinary Team Approach

Tracy Martinez

20 Genomic and Clinical Predictors Associated with Long-Term Success After Bariatric Surgery

Glenn S. Gerhard and G. Craig Wood

21 Medical Approach to a Patient with Postoperative Weight Regain

Robert F. Kushner and Kirsten Webb

22 The Role of Physical Activity in Optimizing Bariatric

Surgery Outcomes.

Dale S. Bond and Wendy C. King

Index. 


\section{Contributors}

Kelly C. Allison, PhD Department of Psychiatry, Perelman School of Medicine at the University of Pennsylvania, Philadelphia, PA, USA

Caroline Apovian, MD, FACP, FACN Department of Medicine, Boston University School of Medicine, Boston, MA, USA

Nutrition and Support Service, Boston Medical Center, Boston, MA, USA

Katherine L. Applegate, PhD Department of Psychiatry, Duke Center for Metabolic and Weight Loss Surgery, Duke University Health System, Durham, NC, USA

Brooke A. Bailer, PhD Department of Psychiatry, Center for Weight and Eating Disorders, Perelman School of Medicine at the University of Pennsylvania, Philadelphia, PA, USA

Peter N. Benotti, MD, FACS Obesity Institute, Geisinger Medical Center, Danville, PA, USA

Chanelle T. Bishop-Gilyard, PsyD, MS Department of Psychiatry, Center for Weight and Eating Disorders, The University of Pennsylvania, Philadelphia, PA, USA

Jeanne Blankenship, MS, RD, CLE Policy Initiatives and Advocacy, American Dietetic Association, Falls Church, VA, USA

Dale S. Bond, PhD Department of Psychiatry and Human Behavior, The Weight Control and Diabetes Research Center, Brown Alpert Medical School, The Miriam Hospital, Providence, RI, USA

Nadia Boulghassoul-Pietrzykowska, MD, FACP Center for Medical Weight Management, Nutrition, Fitness and Lifestyle, Weight \& Life MD, Ewing, NJ, USA

Lauren E. Bradley, MS Department of Psychology, Drexel University, Philadelphia, PA, USA

Meghan L. Butryn, PhD Department of Psychology, Drexel University, Philadelphia, PA, USA

Ray Carvajal, PsyD Department of Psychiatry, Center for Weight and Eating Disorders, Perelman School of Medicine at the University of Pennsylvania, Philadelphia, PA, USA

Perelman School of Medicine at the University of Pennsylvania, Philadelphia, PA, USA

Gregory Dalencourt, MD Faxton St. Luke's Healthcare, William A. Graber, MD, PC Weight Loss Surgery, New Hartford, NY, USA

Martina de Zwaan, MD Department of Psychosomatic Medicine and Psychotherapy, Hannover Medical School, Hanover, Lower Saxony, Germany

Lucy F. Faulconbridge, PhD Department of Psychiatry, Center for Weight and Eating Disorders, Perelman School of Medicine at the University of Pennsylvania, Philadelphia, PA, USA

Evan Forman, PhD Department of Psychology, Drexel University, Philadelphia, PA, USA 
Jennifer Franceschelli, DO Department of GI and Nutrition, Geisinger Obesity Institute, Geisinger Medical Center, Danville, PA, USA

Laura Lewis Frank, PhD, MPH, RD, CD Coordinated Program in Dietetics, Program in Nutrition \& Exercise Physiology (NEP), MultiCare Health System, College of Pharmacy, Washington State University, Tacoma, WA, USA

Frank Nutrition \& Exercise Consulting, LLC, Gig Harbor, WA, USA

Kelli E. Friedman, PhD Department of Psychiatry, Duke Center for Metabolic and Weight Loss Surgery, Duke University Health System, Durham, NC, USA

Margaret M. Furtado, MS, RD, LDN, RYT Department of Bariatric Surgery, University of Maryland Medical Center, Baltimore, MD, USA

Glenn S. Gerhard, MD Institute for Personalized Medicine, Pennsylvania State University, College of Medicine, Hershey, PA, USA

Leslie J. Heinberg, PhD Behavioral Services, Bariatric and Metabolic Institute, Cleveland, $\mathrm{OH}, \mathrm{USA}$

Department of Medicine, Cleveland Clinic Lerner College of Medicine, Cleveland, OH, USA

Wendy C. King, PhD Department of Epidemiology, University of Pittsburgh, Pittsburgh, PA, USA

Robert F. Kushner, MD Division of General Medicine, Department of Medicine, Northwestern University Feinberg School of Medicine, Chicago, IL, USA

Megan E. Lavery, PsyD Cleveland Clinic Foundation, Cleveland, OH, USA

Claire M. LeBrun, MPH, RD, LD Department of Surgery, George Washington Medical Faculty Associates, Washington, DC, USA

Mary Demarest Litchford, PhD, RD, LDN Case Software \& Books, Greensboro, NC, USA

Tracy Martinez, RN, BSN, CBN Wittgrove Bariatric Center, La Jolla, La Jolla, CA, USA

James E. Mitchell, MD Neuropsychiatric Research Institute, University of North Dakota School of Medicine and Health Sciences, Fargo, ND, USA

Julie M. Parrott, MS, RD, CPT Central Jersey Bariatrics, Freehold, NJ, USA

J. Scott Parrott, PhD Department of Interdisciplinary Studies, SHRP, Newark, NJ, USA

Department of Quantitative Methods, School of Public Health, University of Medicine and Dentistry of NJ, Newark, NJ, USA

Toni Piechota, MS, MPH, RD Department of Food and Nutrition, University of California, Davis, Sacramento, CA, USA

Amanda G. Powell, MD Department of Endocrinology, Diabetes, Nutrition and Weight Management, Boston Medical Center, Boston, MA, USA

Jennifer Reiter-Purtill, PhD Department of Behavioral Medicine and Clinical Psychology, Cincinnati Children's Hospital Medical Center, Cincinnati, OH, USA

David B. Sarwer, PhD Department of Psychiatry, Director of Clinical Services Center for Weight and Eating Disorders, Perelman School of Medicine at the University of Pennsylvania, Philadelphia, PA, USA

Christopher Still, DO, FACN, FACP Department of GI and Nutrition, Geisinger Obesity Institute, Geisinger Medical Center, Danville, PA, USA 
J. Graham Thomas, PhD Weight Control and Diabetes Research Center, The Miriam Hospital, The Warren Alpert Medical School of Brown University, Providence, RI, USA

Kirsten Webb, MSN, CNP, CDE Center for Lifestyle Medicine, Northwestern Medical Faculty Foundation, Chicago, IL, USA

G. Craig Wood, MS Geisinger Health System, Geisinger Obesity Institute, Danville, PA, USA Meg H. Zeller, PhD Department of Behavioral Medicine and Clinical Psychology, Cincinnati Children's Hospital Medical Center, University of Cincinnati College of Medicine, Cincinnati, $\mathrm{OH}, \mathrm{USA}$ 